\title{
Deastringent Peel Extracts of Persimmon (Diospyros kaki Thunb. cv. Cheongdo-Bansi) Protect Neuronal PC-12 and SH-SY5Y Cells against Oxidative Stress
}

\author{
Da-Wool Jeong ${ }^{1,2}$, Chi Heung Cho ${ }^{3}$, Jong Suk Lee ${ }^{4}$, Seung Hwan Lee ${ }^{5}$, Taewan Kim ${ }^{5}$, and Dae-Ok Kim ${ }^{1,2 *}$ \\ ${ }^{1}$ Department of Food Science and Biotechnology, Kyung Hee University, Yongin 17104, Republic of Korea \\ ${ }^{2}$ Skin Biotechnology Center, Kyung Hee University, Suwon 16229, Republic of Korea \\ ${ }^{3}$ World Institute of Kimchi, Gwangju 61755, Republic of Korea \\ ${ }^{4}$ Biocenter, Gyeonggido Business and Science Accelerator, Suwon 16229, Republic of Korea \\ ${ }^{5}$ Department of Food Science and Biotechnology, Andong National University, Andong 36729, Republic of Korea
}

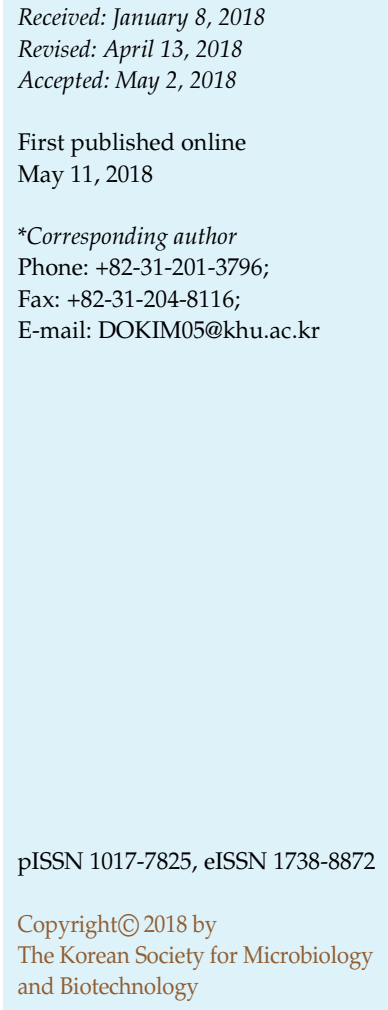

The peel of astringent persimmon (Diospyros kaki Thunb. cv. Cheongdo-Bansi) is a by-product of dried persimmon (gotgam). We investigated if deastringent peel extracts of persimmon cv. Cheongdo-Bansi had antioxidative and neuroprotective properties. Two different extracts were prepared: thermally and nonthermally treated persimmon peel extracts (TPE and NTPE, respectively). Both TPE and NTPE were fractionated sequentially in $n$-hexane, chloroform, ethyl acetate, $n$-butanol, and water. The TPE and NTPE ethyl acetate fractions had the highest total phenolic and flavonoid contents as well as antioxidant capacities among all the fractions. Pretreatment of neuronal PC-12 and SH-SY5Y cells with the TPE and NTPE ethyl acetate fractions increased cell viability after exposure to oxidative stress. The ethyl acetate fraction of TPE attenuated oxidative stress inside both PC-12 and SH-SY5Y cells more effectively than that of NTPE. Furthermore, the TPE and NTPE ethyl acetate fractions inhibited acetylcholinesterase and butyrylcholinesterase. Analysis of ultra-high-performance liquid chromatography-electrospray ionization-tandem mass spectrometry results revealed gallic acid, kaempferol, kaempferol-3-O-galactoside, kaempferol-3-O-glucoside, quercetin, quercetin3-O-galactoside, quercetin-3-O-galactoside-2'-O-gallate, and quercetin-3-O-glucoside as the major phenolics of the TPE and NTPE ethyl acetate fractions. Taken together, these results suggest that the ethyl acetate fraction of deastringent persimmon peel is rich in antioxidants and has potential as a functional food to reduce oxidative stress.

Keywords: Antioxidant, deastringent persimmon peel, by-product, polyphenol, ultra-highperformance liquid chromatography-electrospray ionization-tandem mass spectrometry

\section{Introduction}

Neurodegenerative disorders are diseases in which neurons progressively degenerate and/or nerve cells die [1]. Genetic and non-genetic factors influence neurodegenerative disorders; age is the main non-genetic cause of these disorders [2]. Alzheimer's disease (AD) is a chronic and progressive neurodegenerative disorder characterized by memory deficits and cognitive impairments, and is the most common form of dementia [2]. Factors that are thought to contribute to AD include aging, oxidative stress, accumulation of amyloid beta and tau proteins, and a reduction in levels of neurotransmitters [3]. The brain of patients with $\mathrm{AD}$ is more sensitive to oxidative stress than normal healthy brains, partly due to the fact that antioxidative defense systems such as superoxide dismutase, glutathione peroxidase, and catalase in the brain are overwhelmed by the overproduction of reactive oxygen 
species (ROS) [4].

ROS are produced not only during the course of normal cellular metabolism but also by various external factors such as ultraviolet light and pollution [5]. ROS include the hydroxyl radical $\left(\mathrm{OH}^{*}\right)$, hydrogen peroxide $\left(\mathrm{H}_{2} \mathrm{O}_{2}\right)$, superoxide radical anion $\left(\mathrm{O}_{2}{ }^{\circ}\right)$, and singlet oxygen $\left({ }^{1} \mathrm{O}_{2}\right)$. Accumulation of excessive ROS causes lipid peroxidation, DNA damage, enzyme inactivation, and induction of cell necrosis and apoptosis, which can eventually lead to rheumatism, cancer, aging, and neurodegenerative disorders [6]. Antioxidants can prevent the accumulation of deleterious ROS, which is why interest in natural antioxidants from food-derived materials has been growing [7].

Diospyros kaki, a plant species in the family Ebenaceae, is economically cultivated in East Asian countries such as Korea, Japan, and China for its edible fruit, the persimmon. Persimmon is used as a traditional medicine for conditions such as coughing, hypertension, and frostbites [8]. Various phenolics have been identified in persimmon, including gallic acid, tannin, catechin, epicatechin, quercetin, chlorogenic acid, and caffeic acid [8,9]. Persimmons are generally classified into two groups: sweet (non-astringent) and astringent persimmons, depending on the degree of astringency of the fruit. Most native cultivars in Korea are astringent persimmons. Because of their astringent taste, astringent persimmons are processed by drying only the pulp without the peel (gotgam). To make gotgam, large quantities of deastringent (astringency-removed) peels are discarded as a by-product. The peel of the fruit is known to have a higher total phenolic content and antioxidant capacity than the pulp [10-12]. Peels from dried persimmon manufacturing may be a new functional material, but few studies have investigated if the peels have biological activity. Many phenolics in plants are covalently bonded to insoluble polymers [13]. To obtain high amounts of antioxidants from plants, it is necessary to remove or break these bonds. A variety of methods such as thermal treatment, fermentation, and far-infrared radiation have been used to efficiently obtain bioactive compounds, such as phenolics, from insoluble plant polymers [14-16].

Our aims in this study were to compare the total phenolic and flavonoid contents as well as antioxidant capacities of thermally and nonthermally treated persimmon peels and to investigate their ability to protect two types of neuronal cells (PC-12 and SH-SY5Y cells) against oxidative stress. In addition, major phenolics in persimmon peels were tentatively identified and quantified using ultra-highperformance liquid chromatography-electrospray ionizationtandem mass spectrometry (UHPLC-ESI-MS/MS) and reversed-phase high-performance liquid chromatography (HPLC).

\section{Materials and Methods}

\section{Chemicals}

Folin-Ciocalteu's phenol reagent, 2,2'-azino-bis(3-ethylbenzothiazoline-6-sulfonic acid) (ABTS), 2,2-diphenyl-1-picrylhydrazyl (DPPH), 2,2'-azobis(2-methylpropionamidine) dihydrochloride $(\mathrm{AAPH})$, ascorbic acid, gallic acid, catechin, quercetin-3-Oglucoside, quercetin, kaempferol, 3-(4,5-dimethylthiazol-2-yl)2,5-diphenyltetrazolium bromide (MTT), dimethyl sulfoxide (DMSO), 2',7'-dichlorofluorescin diacetate (DCFH-DA), phosphatebuffered saline, 9-amino-1,2,3,4-tetrahydroacridine hydrochloride hydrate (tacrine), 5,5'-dithiobis(2-nitrobenzoic acid) (DTNB), acetylcholinesterase (AChE), butyrylcholinesterase (BChE), acetylcholine iodide (ATCI), and butyrylthiocholine chloride (BTCC) were purchased from Sigma-Aldrich Co., LLC (USA). Roswell Park Memorial Institute (RPMI)-1640, minimum essential medium (MEM), Dulbecco's phosphate-buffered saline (DPBS), Hank's balanced salt solution (HBSS), penicillin/streptomycin, fetal bovine serum (FBS), and trypsin-EDTA were purchased from Welgene Inc. (Korea). All other chemicals and solvents were of analytical or HPLC grade.

\section{Deastringent Persimmon Peels}

Deastringent peels of astringent persimmon (Diospyros kaki Thunb. cv. Cheongdo-Bansi) harvested in August 2015 were provided by Nature Farm Co. Ltd. (Cheongdo, Republic of Korea), a company that manufactures dried persimmon (gotgam). The deastringent peels were freeze-dried and ground. The moisture content of the freeze-dried deastringent persimmon peels was approximately $5.65 \%$ (data not shown). The freeze-dried deastringent persimmon peels were stored at $-20^{\circ} \mathrm{C}$ prior to use.

\section{Extraction and Fractionation}

The deastringent persimmon peels $(500 \mathrm{mg}$ ) were mixed in $50 \mathrm{ml}$ of $40 \%$ (v/v) aqueous ethanol. The mixture was homogenized using a Polytron homogenizer (PT 10/35; Kinematica, Switzerland) at 15,000 rpm for $2 \mathrm{~min}$, followed by sonication for $10 \mathrm{~min}$. Thermally treated persimmon peel extract (TPE) was reacted in a water bath at $90^{\circ} \mathrm{C}$ for $1 \mathrm{~h}$, and the nonthermally treated persimmon peel extract (NTPE) was left at room temperature for $1 \mathrm{~h}$. Each extract was centrifuged at 2,200 $\times g$ for $10 \mathrm{~min}$. The supernatant was then filtered through Whatman \#2 filter paper (Whatman International Ltd., UK) using a chilled Büchner funnel. The residue was re-extracted using the process described above. The filtrate was evaporated using a rotary evaporator (Eyela, Japan) in a $40^{\circ} \mathrm{C}$ water bath. Extracts were obtained independently three times.

Fractionation was performed using a liquid-liquid extraction method. TPE and NTPE were evaporated to dryness. The solid obtained after evaporation was dissolved in distilled water and 
then an equal volume of each of the following four organic solvents was added in sequence: $n$-hexane, chloroform, ethyl acetate, and $n$-butanol. Fractions were filled with nitrogen gas and stored at $-20^{\circ} \mathrm{C}$ until analysis.

\section{Determination of Total Phenolic Content}

The total phenolic content was measured with a colorimetric assay using Folin-Ciocalteu's phenol reagent [17, 18]. Two hundred microliters of appropriately diluted TPE, NTPE, or gallic acid standard was mixed with $2.6 \mathrm{ml}$ of deionized water. At zero min, $200 \mu \mathrm{l}$ of Folin-Ciocalteu's phenol reagent was added to the mixture. At $6 \mathrm{~min}, 2 \mathrm{ml}$ of $7 \%(\mathrm{w} / \mathrm{v}) \mathrm{Na}_{2} \mathrm{CO}_{3}$ solution was added. At $90 \mathrm{~min}$, the absorbance was measured at $750 \mathrm{~nm}$ using a spectrophotometer (Spectronic 200; Thermo Fisher Scientific Inc., USA). The total phenolic content was expressed as mg gallic acid equivalents (GAE)/100 g dry weight (DW).

\section{Determination of Total Flavonoid Content}

The total flavonoid content was measured using the modified method described by Jia et al. [19]. Briefly, $500 \mu$ l of diluted TPE, NTPE, or catechin standard was mixed with $3.2 \mathrm{ml}$ of deionized water, and then $150 \mu \mathrm{l}$ of $5 \%(\mathrm{w} / \mathrm{v}) \mathrm{NaNO}_{2}$ was added. At $5 \mathrm{~min}$, $150 \mu \mathrm{l}$ of $10 \%(\mathrm{w} / \mathrm{v}) \mathrm{AlCl}_{3}$ was added. At $6 \mathrm{~min}, 1 \mathrm{ml}$ of $1 \mathrm{M} \mathrm{NaOH}$ was added. The absorbance was measured immediately at $510 \mathrm{~nm}$ using a spectrophotometer (Spectronic 200). The total flavonoid content was expressed as mg catechin equivalents (CE)/100 g DW.

\section{Determination of Antioxidant Capacity Using ABTS Radicals}

The antioxidant capacity was measured using an ABTS radical solution [20]. The ABTS radical solution was adjusted to an absorbance of $0.650 \pm 0.020$ at $734 \mathrm{~nm}$. The reaction between ABTS radicals and the appropriately diluted samples was allowed to proceed at $37^{\circ} \mathrm{C}$ for $10 \mathrm{~min}$, and then the decrease in absorbance of the resulting solution was measured at $734 \mathrm{~nm}$ using a spectrophotometer (Spectronic 200). The antioxidant capacity was expressed as mg vitamin C equivalents (VCE)/100 g DW.

\section{Determination of Antioxidant Capacity Using DPPH Radicals}

The antioxidant capacity was also measured using the modified method of Brand-Williams et al. [21] based on the DPPH radical solution. The absorbance of DPPH radicals was set to $0.650 \pm 0.020$ at $517 \mathrm{~nm}$. The reaction between DPPH radicals and the appropriately diluted samples or vitamin $\mathrm{C}$ standard was allowed to proceed at $23^{\circ} \mathrm{C}$ for $30 \mathrm{~min}$. At $30 \mathrm{~min}$, the decrease in absorbance of the resulting solution was monitored at $517 \mathrm{~nm}$ using a spectrophotometer (Spectronic 200). The antioxidant capacity was expressed as mg VCE/100 g DW.

\section{Cell Culture}

The PC-12 cell line, derived from a rat pheochromocytoma, was obtained from the American Type Culture Collection (ATCC, USA). The PC-12 cells were cultured in RPMI-1640 medium containing 10\% heat-inactivated FBS, 100 units $/ \mathrm{ml}$ penicillin, and
$100 \mu \mathrm{g} / \mathrm{ml}$ streptomycin. The SH-SY5Y human neuroblastoma cell line was obtained from the Korean Cell Line Bank (KCLB, Korea). The SH-SY5Y cells were cultured in MEM containing 10\% heat-inactivated FBS, 100 units $/ \mathrm{ml}$ penicillin, and $100 \mu \mathrm{g} / \mathrm{ml}$ streptomycin. Cell culture was performed in a humidified incubator $\left(\mathrm{CO}_{2}\right.$ incubator BB 15; Thermo Electron LED GmbH, Germany) with $5 \% \mathrm{CO}_{2}$ at $37^{\circ} \mathrm{C}$.

\section{Cytotoxicity and Cell Viability}

The effects of the TPE and NTPE ethyl acetate fractions on the cytotoxicity and cell viability of both PC-12 and SH-SY5Y cell lines were evaluated using the MTT assay [22]. PC-12 cells at a density of $2 \times 10^{4}$ cells/well in 96-well plates were precultured for $6 \mathrm{~h}$. After removal of the medium, the PC-12 cells were treated with serum-free medium containing various concentrations of the TPE and NTPE ethyl acetate fractions. After $24 \mathrm{~h}$, the PC-12 cells were treated with $200 \mu \mathrm{M} \mathrm{H}_{2} \mathrm{O}_{2}$ for $1 \mathrm{~h}$, and then with $0.5 \mathrm{mg} / \mathrm{ml}$ MTT for $3 \mathrm{~h}$. SH-SY5Y cells at a density of $1 \times 10^{5}$ cells/well in 96-well plates were precultured for $24 \mathrm{~h}$. After removal of the medium, the SH-SY5Y cells were treated with serum-free medium containing various concentrations of the TPE and NTPE ethyl acetate fractions. After $24 \mathrm{~h}$, the SH-SY5Y cells were treated with $100 \mu \mathrm{M} \mathrm{H}_{2} \mathrm{O}_{2}$ for $1 \mathrm{~h}$, and then with $0.5 \mathrm{mg} / \mathrm{ml}$ MTT for $3 \mathrm{~h}$. The resulting formazan products from both cell lines were dissolved by the addition of DMSO. The amount of MTT formazan dissolved in DMSO was determined by measuring the absorbance using a microplate reader (Infinite M200; Tecan Austria GmbH, Austria) at $570 \mathrm{~nm}$ (detection wavelength) and $630 \mathrm{~nm}$ (reference wavelength). The cytotoxicities of the TPE and NTPE ethyl acetate fractions and the viability of both cell lines were expressed as the percentage (\%) of viable cells relative to control cells $(100 \%)$ that were not exposed to oxidative stress or treated with sample.

\section{Measurement of Intracellular Oxidative Stress}

The levels of intracellular oxidative stress were evaluated using the fluorescent probe DCFH-DA [23]. PC-12 $\left(2 \times 10^{4}\right.$ cells/well in 96-well plates $)$ and SH-SY5Y $\left(1 \times 10^{5}\right.$ cells/well in 96-well plates $)$ cells were precultured for 6 and $24 \mathrm{~h}$, respectively. After treatments with various concentrations of the TPE and NTPE ethyl acetate fractions for $24 \mathrm{~h}$, both cell lines were incubated with $50 \mu \mathrm{M}$ of DCFH-DA in HBSS for $1 \mathrm{~h}$. Next, the PC-12 and SH-SY5Y cells were treated with 30 and $10 \mu \mathrm{M}$ of AAPH in HBSS for $1 \mathrm{~h}$, respectively. Fluorescence was measured using a microplate reader (Infinite M200) at an excitation wavelength of $485 \mathrm{~nm}$ and emission wavelength of $535 \mathrm{~nm}$. The intracellular oxidative stress level was expressed as the percentage (\%) decrease in fluorescence intensity of control cells $(100 \%)$ that were not exposed to oxidative stress or treated with sample.

\section{Inhibition of Cholinesterase}

The AChE inhibition assay was performed using the modified method of Ellman et al. [24]. Cholinesterase inhibitory activity was measured using $\mathrm{AChE}$ and BChE. To evaluate AChE inhibition, 
$20 \mu \mathrm{l}$ of ethyl acetate fractions of TPE and NTPE was mixed with $150 \mu \mathrm{l}$ of DPBS. At zero min, $20 \mu \mathrm{l}$ of $15 \mathrm{mM}$ ATCI and $30 \mu \mathrm{l}$ of $10 \mathrm{mM}$ DTNB were added to the mixture. After incubation at $37^{\circ} \mathrm{C}$ for $10 \mathrm{~min}, 20 \mu \mathrm{l}$ of $\mathrm{AChE}(0.2 \mathrm{U} / \mathrm{ml})$ was added. After reaction at $37^{\circ} \mathrm{C}$ for $30 \mathrm{~min}$, the absorbance was measured at $415 \mathrm{~nm}$ using a microplate reader (Infinite M200). In contrast, BChE inhibition was evaluated by adding $20 \mu \mathrm{l}$ of BTCC $(10 \mathrm{mM})$ instead of ATCI and $20 \mu \mathrm{l}$ of BChE $(0.06 \mathrm{U} / \mathrm{ml})$ instead of AChE. Instead of $20 \mu \mathrm{l}$ of TPE and NTPE ethyl acetate fractions, the same amount of DPBS was used as the control. Tacrine was used as the positive control. The inhibition of $\mathrm{AChE}$ and $\mathrm{BChE}$ was quantified from three independent experiments using $\mu \mathrm{M}$ tacrine equivalents (TE).

\section{UHPLC-ESI-MS/MS Analysis}

Phenolics were identified by using a high-resolution LTQOrbitrap XL mass spectrometer connected to an Accela system (Thermo Fisher Scientific Inc., USA). For polarity-based separation of phenolics, an ACQUITY BEH C ${ }_{18}$ column $(150 \times 2.1 \mathrm{~mm}, 1.7 \mu \mathrm{m}$; Waters Corporation, USA) was used. The injection volume and flow rate were $2 \mu \mathrm{l}$ and $0.3 \mathrm{ml} / \mathrm{min}$, respectively. The solvent gradient compositions of the mobile phases (solvent A, $0.1 \%(\mathrm{v} / \mathrm{v})$ formic acid in deionized water; solvent $\mathrm{B}, 0.1 \%(\mathrm{v} / \mathrm{v})$ formic acid in acetonitrile) were as follows: $95 \% \mathrm{~A} / 5 \% \mathrm{~B}$ at $0 \mathrm{~min}, 95 \% \mathrm{~A} / 5 \%$ $\mathrm{B}$ at $1 \mathrm{~min}, 30 \% \mathrm{~A} / 70 \% \mathrm{~B}$ at $20 \mathrm{~min}, 0 \% \mathrm{~A} / 100 \% \mathrm{~B}$ at $24 \mathrm{~min}, 0 \%$ $\mathrm{A} / 100 \% \mathrm{~B}$ at $27 \mathrm{~min}, 95 \% \mathrm{~A} / 5 \% \mathrm{~B}$ at $28 \mathrm{~min}$, and $95 \% \mathrm{~A} / 5 \% \mathrm{~B}$ at $30 \mathrm{~min}$ [25]. Phenolics were detected at 200-600 nm. The optimized MS conditions in positive ESI mode were as follows: spray voltage, $4.0 \mathrm{kV}$; capillary voltage, $35 \mathrm{~V}$; and temperature, $300^{\circ} \mathrm{C}$. Xcalibur software was used for data acquisition. Phenolics were identified by metabolite profiling using reference literature [26], high-resolution mass, and MS/MS spectral library searches [27].

\section{Quantification of Phenolics Using HPLC Analysis}

Phenolics present in TPE and NTPE ethyl acetate fractions were quantitatively analyzed using an HPLC system (Agilent 1200, Agilent Technologies, Inc., Santa Clara, CA, USA) equipped with a vacuum degasser, quaternary pump, auto-sampler, thermostatted column compartment, and diode array detector. Chromatographic separation was performed using a C18 reversed-phase analytical column (Phenomenex Luna C18(2), $250 \times 4.6 \mathrm{~mm}, 5 \mu \mathrm{m}$; Phenomenex, Torrance, CA, USA). The injection volume was $10 \mu \mathrm{l}$. The flow rate was kept at $1.0 \mathrm{ml} / \mathrm{min}$. Detection wavelengths were set at 280 , 320 , and $370 \mathrm{~nm}$ for phenolics. Solvent gradient compositions of mobile phases (solvent $\mathrm{A}, 0.1 \%(\mathrm{v} / \mathrm{v})$ formic acid in deionized water; solvent $\mathrm{B}, 0.1 \%(\mathrm{v} / \mathrm{v})$ formic acid in acetonitrile) were as follows: $100 \% \mathrm{~A} / 0 \% \mathrm{~B}$ at $0 \mathrm{~min}, 92 \% \mathrm{~A} / 8 \% \mathrm{~B}$ at $4 \mathrm{~min}, 88 \%$ $\mathrm{A} / 12 \% \mathrm{~B}$ at $10 \mathrm{~min}, 84 \% \mathrm{~A} / 16 \% \mathrm{~B}$ at $24 \mathrm{~min}, 75 \% \mathrm{~A} / 25 \% \mathrm{~B}$ at $42.5 \mathrm{~min}, 20 \% \mathrm{~A} / 80 \% \mathrm{~B}$ at $60 \mathrm{~min}, 0 \% \mathrm{~A} / 100 \% \mathrm{~B}$ at $61 \mathrm{~min}$, and $100 \%$ A $/ 0 \%$ B at 70 min. Phenolics of TPE and NTPE ethyl acetate fractions were quantified using standard curves of authentic standards of gallic acid, kaempferol, quercetin, and quercetin-3-Oglucoside.

\section{Statistical Analysis}

All experiments were performed in triplicate. Data are presented as means \pm standard deviation of triplicate determinations. Tests for statistical significance were performed using IBM SPSS software (Version 23, IBM SPSS Statistics Inc., USA). The significance of differences in average values was determined using Duncan's multiple range test $(p<0.05)$.

\section{Results}

\section{Total Phenolic Content}

The total phenolic contents of the five TPE and NTPE fractions are shown in Table 1. The highest total phenolic content was found in the ethyl acetate fraction of both TPE (12,512.7 mg GAE/100 g DW) and NTPE (17,242.9 mg GAE/ $100 \mathrm{~g} \mathrm{DW})$. The total phenolic contents of the TPE fractions decreased as follows: ethyl acetate $>n$-butanol $>$ chloroform $>n$-hexane $>$ water. The total phenolic contents of the

Table 1. Total phenolic and flavonoid contents and antioxidant capacities of five fractions of thermally and nonthermally treated extracts of deastringent Diospyros kaki cv. Cheongdo-Bansi peels.

\begin{tabular}{|c|c|c|c|c|c|c|c|c|}
\hline \multirow[b]{3}{*}{ Fraction } & \multirow{2}{*}{\multicolumn{2}{|c|}{$\begin{array}{c}\text { Total phenolic content } \\
\text { (mg gallic acid equivalents/ } \\
100 \mathrm{~g} \text { dry weight) }\end{array}$}} & \multirow{2}{*}{\multicolumn{2}{|c|}{$\begin{array}{c}\text { Total flavonoid content } \\
\text { (mg catechin equivalents / } \\
100 \text { g dry weight) }\end{array}$}} & \multicolumn{4}{|c|}{$\begin{array}{c}\text { Antioxidant capacity } \\
\text { (mg vitamin C equivalents } / 100 \mathrm{~g} \text { dry weight) }\end{array}$} \\
\hline & & & & & \multicolumn{2}{|c|}{ ABTS $^{1}$} & \multicolumn{2}{|c|}{$\mathrm{DPPH}^{2}$} \\
\hline & Thermal & Nonthermal & Thermal & Nonthermal & Thermal & Nonthermal & Thermal & Nonthermal \\
\hline$n$-Hexane & $1,483.5 \pm 15.9^{3 \mathrm{~cd} 4}$ & $520.1 \pm 73.8^{b}$ & $73.7 \pm 42.3^{b}$ & $9.0 \pm 12.3^{b}$ & $4,613.7 \pm 79.6^{b}$ & $1,781.6 \pm 74.6^{b}$ & $4,241.6 \pm 45.8^{\mathrm{d}}$ & $5,868.0 \pm 84.7^{c}$ \\
\hline Chloroform & $2,347.8 \pm 492.7^{\mathrm{c}}$ & $466.2 \pm 199.2^{b}$ & $136.4 \pm 18.2^{\mathrm{b}}$ & $43.3 \pm 20.4^{\mathrm{b}}$ & $2,964.8 \pm 405.9^{b}$ & $517.3 \pm 185.7^{\mathrm{b}}$ & $6,366.8 \pm 272.3^{c}$ & $7,368.1 \pm 87.9^{c}$ \\
\hline $\begin{array}{l}\text { Ethyl } \\
\text { acetate }\end{array}$ & $12,512.7 \pm 1,059.9^{a}$ & $17,242.9 \pm 2,096.4^{a}$ & $4,478.8 \pm 483.5^{a}$ & $5,616.0 \pm 728.2^{\mathrm{a}}$ & $59,508.2 \pm 2,422.5^{\mathrm{a}}$ & $51,407.9 \pm 3,299.3^{\mathrm{a}}$ & $47,516.4 \pm 1,008.6^{a}$ & $41,717.5 \pm 2,200.3^{a}$ \\
\hline$n$-Butanol & $3,628.2 \pm 917.9^{b}$ & $2,071.3 \pm 191.6^{\mathrm{b}}$ & $521.7 \pm 220.1^{b}$ & $143.5 \pm 26.8^{\mathrm{b}}$ & $4,243.2 \pm 1,334.6^{b}$ & $2,601.9 \pm 255.4^{\mathrm{b}}$ & $10,863.2 \pm 1,254.7^{\mathrm{b}}$ & $13,439.9 \pm 207.0^{b}$ \\
\hline Water & $1,060.3 \pm 126.3^{\mathrm{d}}$ & $402.1 \pm 38.1^{\mathrm{b}}$ & $104.9 \pm 7.8^{\mathrm{b}}$ & $22.6 \pm 2.4^{\mathrm{b}}$ & $606.3 \pm 179.2^{c}$ & $557.8 \pm 34.5^{\mathrm{b}}$ & $1,954.7 \pm 116.3^{\mathrm{e}}$ & $1,220.7 \pm 31.7^{\mathrm{d}}$ \\
\hline
\end{tabular}

${ }^{1}$ ABTS: 2,2'-Azino-bis(3-ethylbenzothiazoline-6-sulfonic acid) radical scavenging assay.

${ }^{2}$ DPPH: 2,2-Diphenyl-1-picrylhydrazyl radical scavenging assay.

${ }^{3}$ Data are expressed as the means \pm standard deviations $(n=3)$.

${ }^{4}$ Means with different superscripts in the same column indicate significant difference by Duncan's multiple range test $(p<0.05)$ 
NTPE fractions decreased as follows: ethyl acetate $>n$ butanol $>n$-hexane $>$ chloroform $>$ water.

\section{Total Flavonoid Content}

The total flavonoid contents of the five TPE and NTPE fractions are shown in Table 1. The highest total flavonoid content was found in the ethyl acetate fraction of both TPE (4,478.8 mg CE/100 g DW) and NTPE (5,616.0 mg CE/ $100 \mathrm{~g} \mathrm{DW})$. The total flavonoid contents of both TPE and NTPE fractions decreased as follows: ethyl acetate $>n$ butanol $>$ chloroform $>$ water $>n$-hexane.

\section{Antioxidant Capacity}

The antioxidant capacities of the five TPE and NTPE fractions measured using the ABTS and DPPH assays are shown in Table 1. In the ABTS assay, the ethyl acetate fractions of both TPE and NTPE had the highest antioxidant capacities of 59,508.2 and 51,407.9 mg VCE/100 g DW, respectively. The antioxidant capacities of the TPE fractions decreased as follows: ethyl acetate $>n$-hexane $>n$-butanol $>$ chloroform > water; whereas the antioxidant capacities of the NTPE fractions decreased as follows: ethyl acetate $>n$ butanol $>n$-hexane $>$ water $>$ chloroform.

In the DPPH assay, the highest antioxidant capacities were also found in the ethyl acetate fractions of both TPE (47,516.4 $\mathrm{mg}$ VCE/100 $\mathrm{g}$ DW) and NTPE (41,717.5 mg $\mathrm{VCE} / 100 \mathrm{~g} \mathrm{DW})$. The antioxidant capacities of the TPE and NTPE fractions decreased as follows: ethyl acetate $>n$ butanol $>$ chloroform $>n$-hexane $>$ water. The ethyl acetate fractions of both TPE and NTPE showed at least 10-fold higher antioxidant capacities than the other fractions. Therefore, all subsequent in vitro cell cultures and enzyme assays to evaluate the potential neuroprotective effects of the fractions were conducted using only the ethyl acetate fractions.

Cytotoxicity of TPE and NTPE Ethyl Acetate Fractions and Their Ability to Protect against Oxidative StressInduced Loss of Cell Viability

The cytotoxicity of the ethyl acetate fractions was examined to determine at what concentrations they were not toxic. Cell viability of $90 \%$ or above was considered indicative of lack of cytotoxicity.

Both the TPE and NTPE ethyl acetate fractions had no cytotoxicity against PC-12 cells up to $50 \mu \mathrm{g} / \mathrm{ml}$ (Fig. 1A). Oxidative stress $\left(200 \mu \mathrm{M}\right.$ of $\left.\mathrm{H}_{2} \mathrm{O}_{2}\right)$ decreased the viability of PC-12 cells up to approximately $47 \%$ (Fig. 1B). Pretreatment of cells with the TPE and NTPE ethyl acetate fractions increased the viability of PC-12 cells exposed to oxidative stress. Cells pretreated with the TPE and NTPE ethyl acetate fractions at 25 and $12.5 \mu \mathrm{g} / \mathrm{ml}$ had viabilities of approximately $64 \%$ and $62 \%$, respectively (Fig. 1B).

The TPE and NTPE ethyl acetate fractions had no cytotoxicity against SH-SY5Y cells up to $50 \mu \mathrm{g} / \mathrm{ml}$ (Fig. 2A). Oxidative stress $\left(100 \mu \mathrm{M} \mathrm{H} \mathrm{H}_{2} \mathrm{O}_{2}\right)$ reduced the viability of SH-SY5Y cells to approximately $41 \%$ (Fig. 2B). Pretreatment of SH-SY5Y cells with the TPE and NTPE ethyl acetate fractions increased their viability after exposure to oxidative stress. Treatment of SH-SY5Y cells with $50 \mu \mathrm{g} / \mathrm{ml}$ of the TPE and NTPE ethyl acetate fractions showed viabilities of approximately $50 \%$ and $50 \%$, respectively (Fig. 2B).
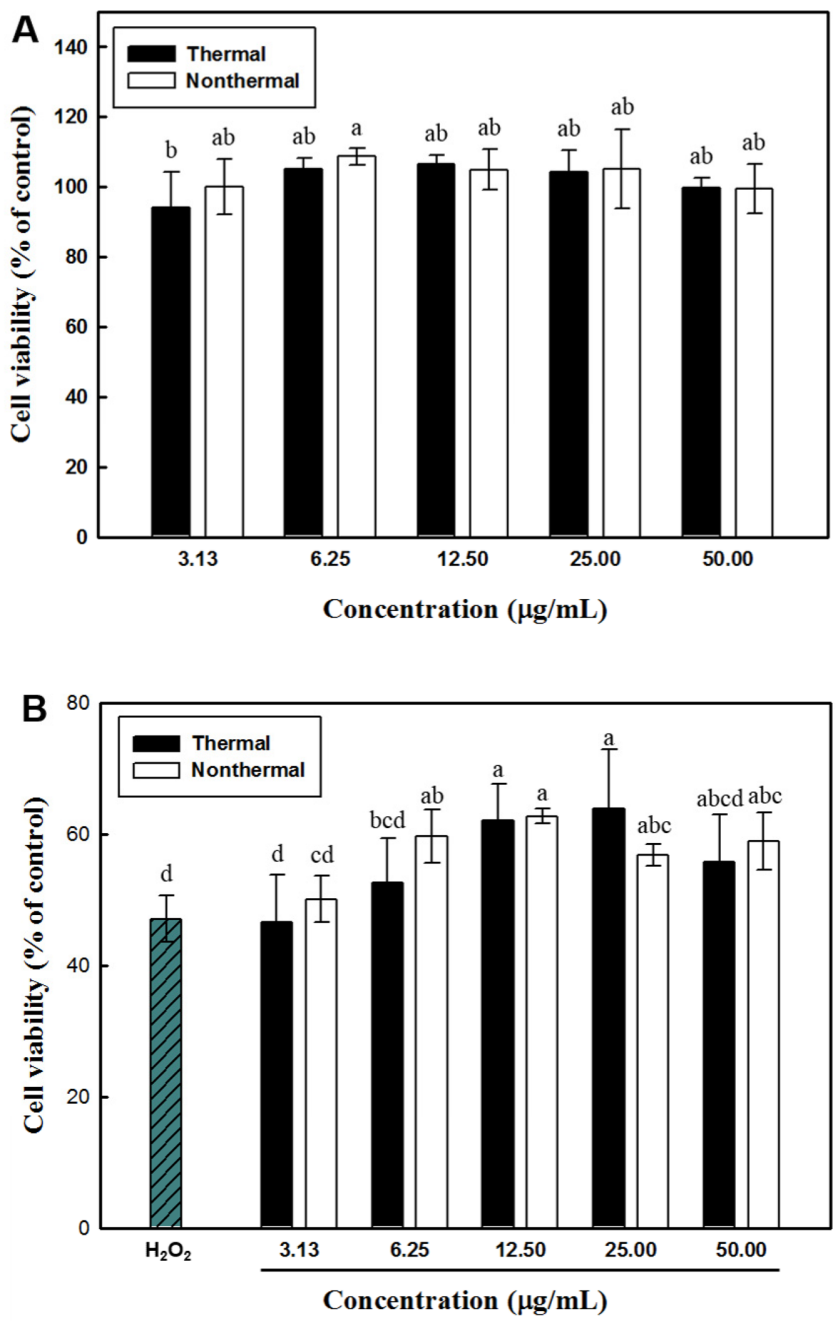

Fig. 1. Cytotoxic (A) and protective (B) effects of the ethyl acetate fractions of thermally and nonthermally treated extracts of deastringent Diospyros kaki Thunb. cv. CheongdoBansi peels in neuronal PC-12 cells exposed to oxidative stress $\left(\mathrm{H}_{2} \mathrm{O}_{2}\right)$, as assessed by the MTT assay. 

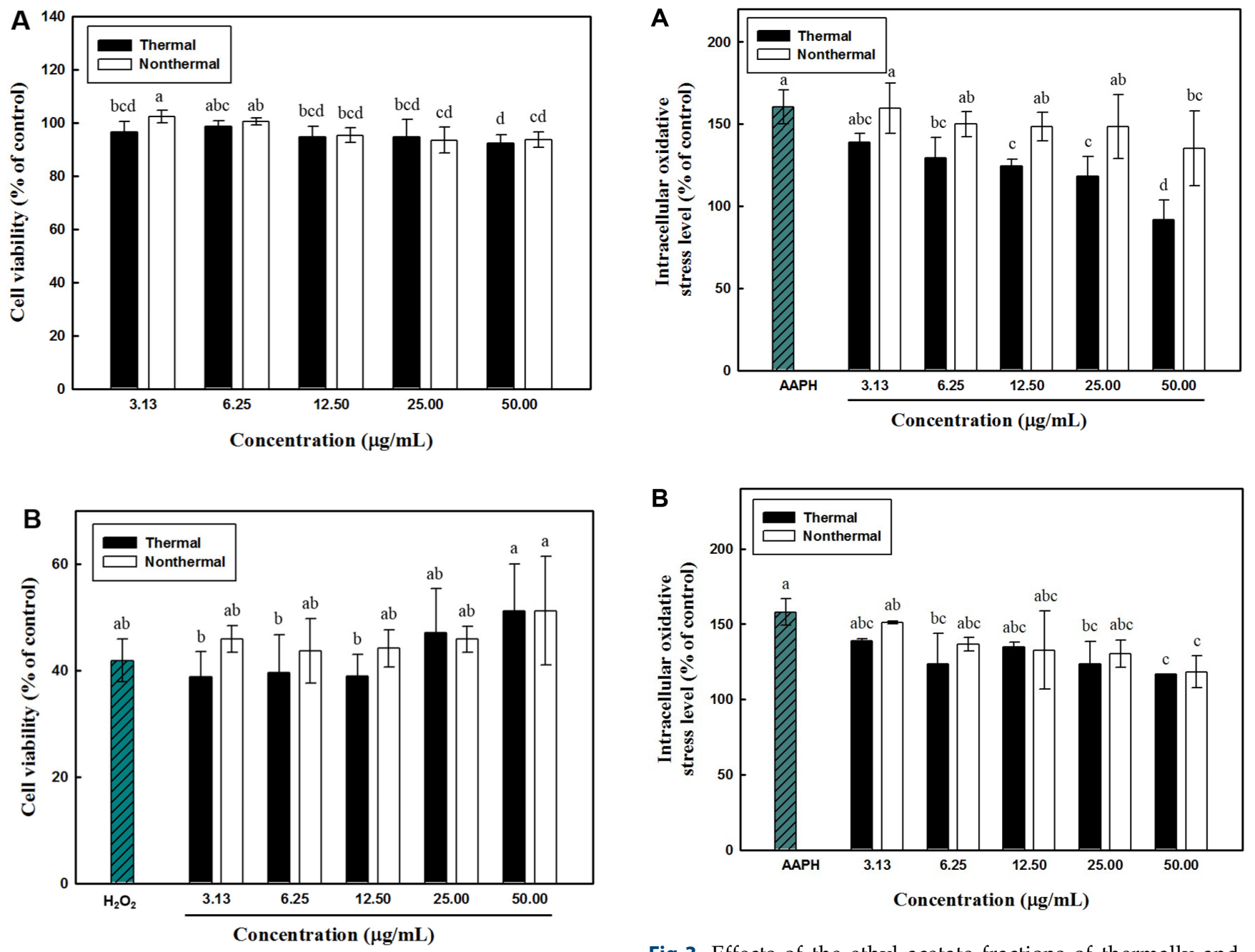

Fig. 2. Cytotoxic (A) and protective (B) effects of the ethyl acetate fractions of thermally and nonthermally treated extracts of deastringent Diospyros kaki Thunb. cv. CheongdoBansi peels in neuronal SH-SY5Y cells exposed to oxidative stress $\left(\mathrm{H}_{2} \mathrm{O}_{2}\right)$, as assessed by the MTT assay.

\section{Intracellular Oxidative Stress}

AAPH increased the oxidative stress inside PC-12 cells up to $160 \%$ compared with the control (100\%, Fig. 3A). Pretreatment of PC-12 cells with the TPE and NTPE ethyl acetate fractions reduced the AAPH-induced intracellular oxidative stress (Fig. 3A). Treatment of PC-12 cells with $50 \mu \mathrm{g} / \mathrm{ml}$ of the TPE ethyl acetate fraction decreased the AAPH-induced intracellular oxidative stress to $90 \%$ of that measured in control cells (Fig. 3A). AAPH treatment also increased the intracellular oxidative stress in SH-SY5Y cells to $160 \%$ of the control level. SH-SY5Y cells pretreated with the TPE or NTPE ethyl acetate fractions had lower

Fig 3. Effects of the ethyl acetate fractions of thermally and nonthermally treated extracts of deastringent Diospyros kaki Thunb. cv. Cheongdo-Bansi peels on AAPH-induced intracellular oxidative stress in neuronal PC-12 (A) and SHSY5Y (B) cells, as assessed using the DCFH-DA assay.

oxidative stress compared with cells exposed to oxidative stress only (Fig. 3B).

\section{Inhibition of Cholinesterases}

Inhibition of AChE by the TPE and NTPE ethyl acetate fractions is shown in Fig. 4A. The TPE ethyl acetate fractions at $50 \mu \mathrm{g} / \mathrm{ml}$ had a TE of approximately $75.1 \mu \mathrm{M}$, whereas the NTPE ethyl acetate fraction at $50 \mu \mathrm{g} / \mathrm{ml}$ had a TE of $136.5 \mu \mathrm{M}$, which is approximately 1.8-fold higher than the TE of the TPE ethyl acetate fraction. Inhibition of BChE by the TPE and NTPE ethyl acetate fractions is shown in Fig. 4B. The TPE ethyl acetate fraction at $50 \mu \mathrm{g} / \mathrm{ml}$ had a TE of $6.8 \mu \mathrm{M}$, whereas the NTPE ethyl acetate 

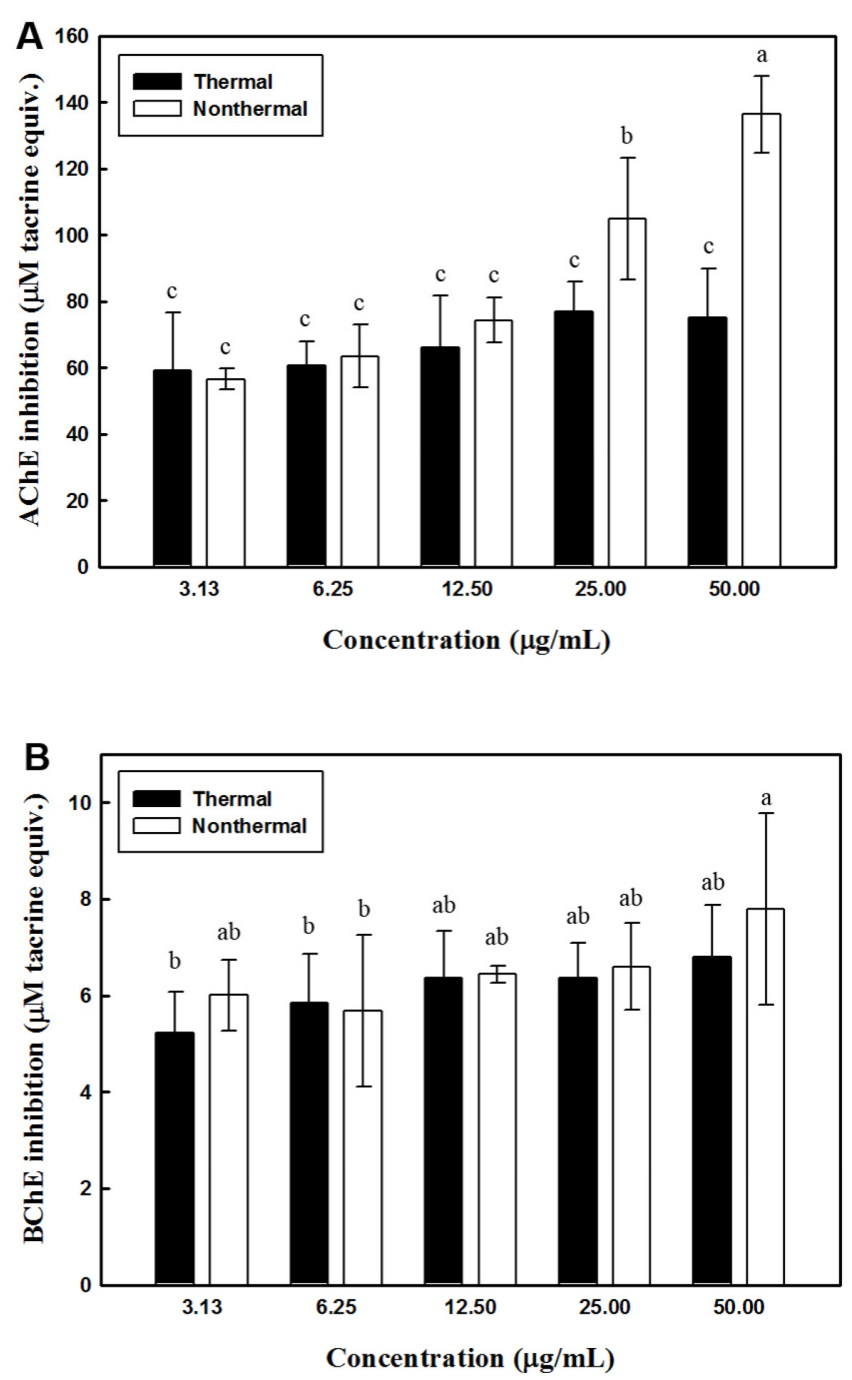

Fig 4. Inhibitory effects of the ethyl acetate fractions of thermally and nonthermally treated extracts of deastringent Diospyros kaki Thunb. cv. Cheongdo-Bansi peels on acetylcholinesterase (AChE) (A) and butyrylcholinesterase (BChE) (B) activities.

fraction at $50 \mu \mathrm{g} / \mathrm{ml}$ had a TE of $7.8 \mu \mathrm{M}$. The NTPE ethyl acetate fraction inhibited the $\mathrm{AChE}$ and $\mathrm{BChE}$ activities to a greater extent than the TPE ethyl acetate fraction (Fig. 4).

\section{Identification and Quantification of Phenolics Using UHPLC-ESI-MS/MS and Reversed-Phase HPLC}

The elution profile of phenolics in the TPE and NTPE ethyl acetate fractions obtained by UHPLC is shown in Fig. 5. The identity and amount of major phenolics present in the ethyl acetate fractions of both TPE and NTPE are presented in Table 2. The major phenolics in the TPE and NTPE ethyl acetate fractions of deastringent peels of D. kaki
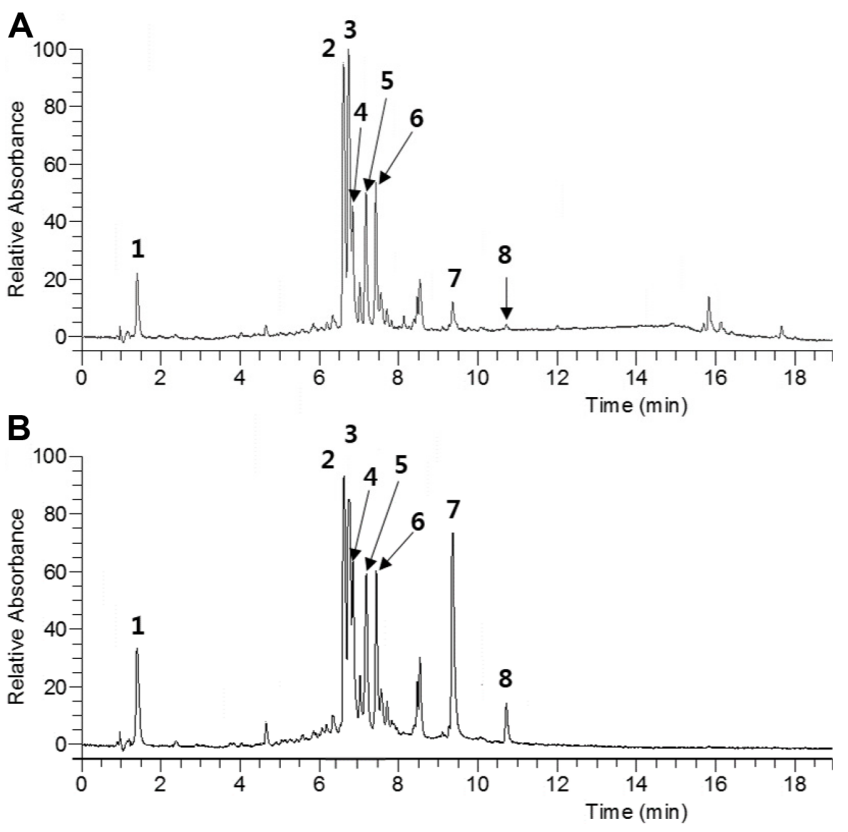

Fig 5. UHPLC chromatograms of the phenolics present in the ethyl acetate fractions of thermally (A) and nonthermally (B) treated extracts of deastringent Diospyros kaki Thunb. cv. Cheongdo-Bansi peels.

Peak 1, gallic acid; peak 2, quercetin-3-O-galactoside; peak 3 , quercetin3-O-glucoside; peak 4, quercetin-3-O-galactoside-2'-O-gallate; peak 5, kaempferol-3-O-galactoside; peak 6, kaempferol-3-O-glucoside; peak 7, quercetin; and peak 8, kaempferol.

Thunb. cv. Cheongdo-Bansi identified using UHPLC-ESIMS/MS were gallic acid, kaempferol, kaempferol-3-Ogalactoside, kaempferol-3-O-glucoside, quercetin, quercetin3-O-galactoside, quercetin-3-O-galactoside-2'-O-gallate, and quercetin-3-O-glucoside. The sum of the eight phenolics identified in the TPE and NTPE ethyl acetate fractions was $26.7 \pm 4.0$ and $26.0 \pm 3.4 \mathrm{mg} / 100 \mathrm{~g}$ DW, respectively (data not shown).

\section{Discussion}

As shown in Table 1, the ethyl acetate fractions of TPE and NTPE exhibited the highest total phenolic and flavonoid contents as well as antioxidant capacities among the various fractions evaluated. Consistent with these results, a previous study reported that the ethyl acetate fractions of dried persimmon had the highest total phenolic and flavonoid contents, in addition to antioxidant capacity among the various fractions [28]. The ethyl acetate fractions of fresh persimmon cv. Sangjudungsi (D. kaki Thunb.), a major astringent cultivar in Korea, was also reported to 
Table 2. Identification and quantification of phenolics in the ethyl acetate fractions of thermally and nonthermally treated extracts of deastringent Diospyros kaki Thunb. cv. Cheongdo-Bansi peels using UHPLC-ESI-MS/MS and reversed-phase HPLC.

\begin{tabular}{cccclcc}
\hline Peak No. & $\begin{array}{c}\text { Retention time } \\
(\mathrm{min})\end{array}$ & $\begin{array}{c}\text { Molecular ion } \\
\left(\mathrm{m} / z,[\mathrm{M}+\mathrm{H}]^{+}\right)\end{array}$ & $\begin{array}{c}\text { Formula } \\
\left([\mathrm{M}+\mathrm{H}]^{+}\right)\end{array}$ & \multicolumn{2}{c}{$\begin{array}{c}\text { Identification } \\
\text { Thermal }\end{array}$} & \multicolumn{2}{c}{$\begin{array}{c}\text { Concentrations } \\
(\mathrm{mg} / 100 \mathrm{~g} \text { dry weight })\end{array}$} \\
\cline { 5 - 7 } & 1.40 & 171.0302 & $\mathrm{C}_{7} \mathrm{H}_{7} \mathrm{O}_{5}$ & Gallic acid & $3.15 \pm 0.05$ & $5.11 \pm 0.06$ \\
2 & 6.62 & 465.1052 & $\mathrm{C}_{21} \mathrm{H}_{21} \mathrm{O}_{12}$ & Quercetin-3-O-galactoside & $5.82 \pm 0.18^{1}$ & $4.76 \pm 0.08^{1}$ \\
3 & 6.74 & 465.1052 & $\mathrm{C}_{21} \mathrm{H}_{21} \mathrm{O}_{12}$ & Quercetin-3-O-glucoside & $12.26 \pm 0.36$ & $10.45 \pm 0.83$ \\
4 & 6.85 & 671.1150 & $\mathrm{C}_{28} \mathrm{H}_{25} \mathrm{O}_{16}$ & Quercetin-3-O-galactoside-2'-O-gallate & $0.78 \pm 0.05^{1}$ & $0.80 \pm 0.04^{1}$ \\
5 & 7.19 & 449.1105 & $\mathrm{C}_{21} \mathrm{H}_{21} \mathrm{O}_{11}$ & Kaempferol-3-O-galactoside & $2.22 \pm 0.05^{2}$ & $2.08 \pm 0.03^{2}$ \\
6 & 7.44 & 449.1100 & $\mathrm{C}_{21} \mathrm{H}_{21} \mathrm{O}_{11}$ & Kaempferol-3-O-glucoside & $2.08 \pm 0.04^{2}$ & $1.75 \pm 0.02^{2}$ \\
7 & 9.36 & 303.0507 & $\mathrm{C}_{15} \mathrm{H}_{11} \mathrm{O}_{7}$ & Quercetin & $0.35 \pm 0.05$ & $0.91 \pm 0.10$ \\
8 & 10.72 & 287.0557 & $\mathrm{C}_{15} \mathrm{H}_{11} \mathrm{O}_{6}$ & Kaempferol & $0.15 \pm 0.00$ & $0.15 \pm 0.01$ \\
\hline
\end{tabular}

${ }^{1}$ Data are expressed as quercetin equivalents.

${ }^{2}$ Data are expressed as kaempferol equivalents.

show the highest levels of total phenolics and flavonoids, as well as have the greatest antioxidant capacity among the various fractions evaluated [29]. In our study, thermal treatments generally increased the total phenolic and flavonoid contents as well as antioxidant capacity of deastringent peel extracts of D. kaki Thunb. cv. CheongdoBansi relative to nonthermal treatment.

We attributed the increase in antioxidant capacity obtained by heat treatment to the dissociation of phenolics bonded with polymers such as proteins and carbohydrates, and the degradation of polymeric phenolics to smaller molecules through heating. Bound forms of phenolics have been reported to be converted to free forms by heating, which results in increased antioxidant capacity $[16,30]$. The generation of new phenolics during the heating process may also increase the antioxidant capacity [31]. The reducing power, DPPH and ABTS radical scavenging activities, and $\beta$-carotene blanching inhibition activity of persimmon juice were previously reported to increase as the heating time and temperature were increased [15].

In this study, we evaluated the in vitro neuroprotective effects of the TPE and NTPE ethyl acetate fractions in neuronal PC-12 and SH-SY5Y cells exposed to oxidative stress. PC-12 cells are derived from a pheochromocytoma of the rat adrenal medulla, whereas SH-SY5Y cells are human-derived cells. In cells with an intact metabolism, mitochondrial dehydrogenases reduce yellow watersoluble MTT to dark purple water-insoluble formazan crystals [22]. The greater the amount of insoluble formazan, the higher the viability of neuronal cells. Both the TPE and NTPE ethyl acetate fractions at concentrations of 12.5-25.0 and $6.25-50.0 \mu \mathrm{g} / \mathrm{ml}$, respectively, significantly $(p<0.05)$ increased the viability of oxidatively stressed PC-12 cells compared with the stress control (Fig. 1B). Persimmon peel extract has been reported to protect N18-RE-105 cells from glutamate-induced cytotoxicity in contrast to persimmon extracts from other parts of the fruit or plant [32]. Persimmon peel extract has also been reported to protect PC-12 cells from glucose-oxygen-serum deprivationinduced ischemic injury [33]. The viability of oxidatively stressed SH-SY5Y cells, however, was not significantly $(p<0.05)$ increased by treatments of either ethyl acetate fraction, regardless of concentration, compared with the stress control (Fig. 2B).

The AAPH-induced oxidative stress inside PC-12 and SH-SY5Y cells was measured using the DCFH-DA assay. DCFH-DA can permeate through the cell membrane, whereupon it is deacetylated by an intracellular esterase and degraded into a non-fluorescent $2^{\prime}, 7^{\prime}$-dichlorofluorescin. $2^{\prime}, 7^{\prime}$-Dichlorofluorescin oxidized by ROS is converted into $2^{\prime}, 7^{\prime}$-dichlorofluorescein, which fluoresces green. The levels of intracellular oxidative stress can therefore be assessed by measuring the fluorescence intensity. The TPE ethyl acetate fraction reduced the AAPH-induced intracellular oxidative stress to a greater extent than the NTPE ethyl acetate fraction in both PC-12 and SH-SY5Y cells (Fig. 3). Treatment of PC-12 cells with $50.0 \mu \mathrm{g} / \mathrm{ml}$ TPE ethyl acetate fraction restored cell viability to a similar level as that of the control group (Fig. 3A). The ethyl acetate fractions of TPE and NTPE had considerable amounts of total phenolics (Table 1). The total phenolic content is known to be highly linearly correlated with antioxidant capacity [11, 
34], which suggests that phenolics may serve as antioxidants to decrease intracellular oxidative stress in neuronal cells.

Procyanidins found in persimmon peel have been reported to protect TIG-1 fibroblasts from oxidative stress in response to $\mathrm{H}_{2} \mathrm{O}_{2}$-induced aging [35]. As a group of polyphenols, procyanidins have been reported to have a higher antioxidant capacity than vitamin C [34]. Both the TPE and NTPE ethyl acetate fractions had neuroprotective effects against oxidative stress, due in part to an increase in cell viability (Figs. 1 and 2) and reduction in intracellular oxidative stress (Fig. 3).

$\mathrm{AChE}$ is a major cholinesterase in the brain, and BChE activity is known to increase gradually in Alzheimer-type dementia [36]. These enzymes break down acetylcholine into choline and acetate to terminate neurotransmission. To treat Alzheimer's patients with dementia, cholinergic neurotransmitters need to be kept in the synaptic cleft for a longer time; this can be achieved by inhibiting cholinergic enzymes such as AChE and BChE. In this study, tacrine was used as a standard. Tacrine as a cholinesterase inhibitor was used to treat AD, but it is currently not used because of its many side effects such as hepatotoxicity [37].

$\mathrm{AChE}$ and BChE were inhibited by the TPE and NTPE ethyl acetate fractions (Fig. 4). Both ethyl acetate fractions inhibited AChE more strongly than BChE. At $50 \mu \mathrm{g} / \mathrm{ml}$, the NTPE ethyl acetate fraction inhibited BChE to a greater extent than the TPE ethyl acetate fraction (Fig. 4). The ethyl acetate fraction of NTPE had a higher total phenolic content than that of TPE, corresponding to the higher AChE and BChE inhibitory activities of the NTPE fraction. In contrast to our findings, it was previously reported that the total phenolic content in various tea infusions was not correlated with AChE inhibitory activity [38]. In more detail, aqueous tea infusions of strawberry and walnut had a considerable total phenolic content and inhibited AChE [38]. AChE was reported to be inhibited by seed extracts of native Korean persimmon cultivars, including Gyungsan Bansi [39].

Major phenolics were qualitatively identified using UHPLC-ESI-MS/MS and quantified using reversed-phase HPLC (Fig. 5 and Table 2). One phenolic acid (gallic acid), four quercetin derivatives (quercetin, quercetin-3-Ogalactoside, quercetin-3-O-galactoside-2'-O-gallate, and quercetin-3-O-glucoside), and three kaempferol derivatives (kaempferol, kaempferol-3-O-galactoside, and kaempferol3-O-glucoside) were identified in the TPE and NTPE ethyl acetate fractions in this study. These phenolic acids and flavonols are known antioxidants [20]. Quercetin, found in the TPE and NTPE ethyl acetate fractions in this study, inhibited AChE from brain tissues of ICR mice exposed to the neurotoxin trimethyltin in a dose-dependent manner [40]. Quercetin has been reported to inhibit AChE and $\mathrm{BChE}$ in a concentration-dependent manner [41]. Gallic acid, found in persimmon peel in this study, has also been reported to inhibit AChE [38]. Therefore, the phenolics in the TPE and NTPE ethyl acetate fractions were likely responsible for the observed inhibition of cholinesterases.

It was previously reported that gallic acid was the most abundant phenolic compound in D. kaki L. cv. Mopan, a Chinese persimmon cultivar [42]. Persimmon has one of the highest antioxidant capacities of fruits because of the abundance of gallic acid [42-44]. Persimmon peel also contains abundant tannins, which may contain gallic acid residues linked with glucose via glycosidic bonds [9]. A variety of flavonoids have been identified in persimmon leaves, including quercetin, kaempferol, and quercetin-3$O$-glucoside, which were found in TPE and NTPE in our study [26].

In a previous study of citrus peel extract, phenolic acids were divided into four fractions [31]. Heat treatment increased the free phenolic acid fraction, but decreased the soluble ester, glycoside, and insoluble ester-bound fractions [31]. Thermal treatment decreased the total phenolic content of citrus peel extract to a greater extent than nonthermal treatment [31], suggesting that some phenolic acids were heat-labile and destroyed. However, the antioxidant capacity measured by the ABTS and FRAP assays increased as heating time and temperature increased, partly due to the formation of free forms of the lower molecular-weight phenolics [45]. In our study, thermal treatment tended to increase the antioxidant capacity, whereas the total phenolic content decreased in response to thermal treatment (Table 1). In addition, the UHPLC-ESI-MS/MS chromatograms (Fig. 5) revealed unknown compounds in the TPE ethyl acetate fractions eluted after $14 \mathrm{~min}$, indicating that phenolic fingerprinting was influenced by thermal treatment.

In conclusion, we have investigated the antioxidant and neuroprotective properties of astringent persimmon (D. kaki Thunb. cv. Cheongdo-Bansi) peel with the astringency removed after gotgam processing. The TPE and NTPE ethyl acetate fractions had the highest total phenolic and flavonoid contents as well as antioxidant capacities among the five fractions tested in this study. The TPE and NTPE ethyl acetate fractions increased the cell viability of both neuronal PC-12 and SH-SY5Y cells exposed to oxidative stress, in part by reducing oxidative stress inside the neuronal cells. The NTPE ethyl acetate fraction inhibited AChE and BChE to a greater extent than the TPE ethyl 
acetate fraction. UHPLC-ESI-MS/MS analysis of the TPE and NTPE ethyl acetate fractions revealed the presence of phenolic acid (gallic acid) and seven flavonols (kaempferol, kaempferol-3-O-galactoside, kaempferol-3-O-glucoside, quercetin, quercetin-3-O-galactoside, quercetin-3-O-galactoside$2^{\prime}$-O-gallate, and quercetin-3-O-glucoside) as the major phenolics. These results demonstrate that the ethyl acetate fraction of deastringent persimmon peel, a by-product of dried persimmon processing, has antioxidative and cellprotective effects and can therefore potentially be used as a functional material to protect neuronal cells and inhibit cholinesterase activity. Further studies are warranted to determine the molecular mechanisms underlying the neuroprotective effects of the phenolics found in deastringent persimmon peel and to examine whether these phenolics can ameliorate memory deficits and cognitive impairment in in vivo animal models of neurodegenerative diseases.

\section{Acknowledgments}

This research was supported by the Forest Science Technology Research and Development Project (2016017D101719AB02) of the Korea Forestry Promotion Institute, Korea Forest Service, Republic of Korea.

\section{Conflict of Interest}

The authors have no financial conflicts of interest to declare.

\section{References}

1. Singh RP, Sharad S, Kapur S. 2004. Free radicals and oxidative stress in neurodegenerative diseases: relevance of dietary antioxidants. J. Indian Acad. Clin. Med. 5: 218-225.

2. Esposito E, Rotilio D, Matteo VD, Di Giulio C, Cacchio M, Algeri S. 2002. A review of specific dietary antioxidants and the effects on biochemical mechanisms related to neurodegenerative processes. Neurobiol. Aging 23: 719-735.

3. Mattson MP. 2004. Pathways towards and away from Alzheimer's disease. Nature 430: 631-639.

4. Marcus DL, Thomas C, Rodriguez C, Simberkoff K, Tsai JS, Strafaci JA, et al. 1998. Increased peroxidation and reduced antioxidant enzyme activity in Alzheimer's disease. Exp. Neurol. 150: 40-44.

5. Birben E, Sahiner UM, Sackesen C, Erzurum S, Kalayci O. 2012. Oxidative stress and antioxidant defense. World Allergy Organ. J. 5: 9-19.

6. Gupta RK, Patel AK, Shah N, Choudhary AK, Jha UK,
Yadav UC, et al. 2014. Oxidative stress and antioxidants in disease and cancer: a review. Asian Pac. J. Cancer Prev. 15: 4405-4409.

7. Nimse SB, Pal D. 2015. Free radicals, natural antioxidants, and their reaction mechanisms. RSC Adv. 5: 27986-28006.

8. Yaqub S, Farooq U, Shafi A, Akram K, Murtaza MA, Kausar T, et al. 2016. Chemistry and functionality of bioactive compounds present in persimmon. J. Chem. 2016: 3424025.

9. Butt MS, Sultan MT, Aziz M, Naz A, Ahmed W, Kumar N, et al. 2015. Persimmon (Diospyros kaki) fruit: hidden phytochemicals and health claims. EXCLI J. 14: 542-561.

10. Kim H, Moon JY, Kim H, Lee D-S, Cho M, Choi H-K, et al. 2010. Antioxidant and antiproliferative activities of mango (Mangifera indica L.) flesh and peel. Food Chem. 121: 429-436.

11. Lee I, Lee BH, Eom SH, Oh C-S, Kang H, Cho Y-S, et al. 2015. Antioxidant capacity and protective effects on neuronal PC-12 cells of domestic bred kiwifruit. Korean J. Hort. Sci. Technol. 33: 259-267.

12. Park J-H, Lee M, Park E. 2014. Antioxidant activity of orange flesh and peel extracted with various solvents. Prev. Nutr. Food Sci. 19: 291-298.

13. Shahidi F, Yeo J. 2016. Insoluble-bound phenolics in food. Molecules 21: 1216.

14. Jeong S-M, Kim S-Y, Kim D-R, Jo S-C, Nam KC, Ahn DU, et al. 2004. Effect of heat treatment on the antioxidant activity of extracts from citrus peels. J. Agric. Food Chem. 52: 3389-3393.

15. Lee D-W, Lee S-C. 2012. Effect of heat treatment condition on the antioxidant and several physiological activities of non-astringent persimmon fruit juice. Food Sci. Biotechnol. 21: 815-822.

16. Lee S-C, Jeong S-M, Kim S-Y, Park H-R, Nam KC, Ahn DU. 2006. Effect of far-infrared radiation and heat treatment on the antioxidant activity of water extracts from peanut hulls. Food Chem. 94: 489-493.

17. Kim D-O, Chun OK, Kim YJ, Moon H-Y, Lee CY. 2003. Quantification of polyphenolics and their antioxidant capacity in fresh plums. J. Agric. Food Chem. 51: 6509-6515.

18. Singleton VL, Rossi JA Jr. 1965. Colorimetry of total phenolics with phosphomolybdic-phosphotungstic acid reagents. Am. J. Enol. Vitic. 16: 144-158.

19. Jia Z, Tang M, Wu J. 1999. The determination of flavonoid contents in mulberry and their scavenging effects on superoxide radicals. Food Chem. 64: 555-559.

20. Kim D-O, Lee CY. 2004. Comprehensive study on vitamin C equivalent antioxidant capacity (VCEAC) of various polyphenolics in scavenging a free radical and its structural relationship. Crit. Rev. Food Sci. Nutr. 44: 253-273.

21. Brand-Williams W, Cuvelier ME, Berset C. 1995. Use of a free radical method to evaluate antioxidant activity. LWT Food Sci. Technol. 28: 25-30.

22. Heo H-J, Cho H-Y, Hong B, Kim H-K, Kim E-K, Kim B-G, et al. 2001. Protective effect of 4',5-dihydroxy-3',6,7-trimethoxyflavone from Artemisia asiatica against $\mathrm{A} \beta$-induced oxidative stress 
in PC12 cells. Amyloid 8: 194-201.

23. Wolfe KL, Liu RH. 2007. Cellular antioxidant activity (CAA) assay for assessing antioxidants, foods, and dietary supplements. J. Agric. Food Chem. 55: 8896-8907.

24. Ellman GL, Courtney KD, Andres V Jr, Featherstone RM. 1961. A new and rapid colorimetric determination of acetylcholinesterase activity. Biochem. Pharmacol. 7: 88-95.

25. Choi J, An X, Lee BH, Lee JS, Heo HJ, Kim T, et al. 2015. Protective effects of bioactive phenolics from jujube (Ziziphus jujuba) seeds against $\mathrm{H}_{2} \mathrm{O}_{2}$-induced oxidative stress in neuronal PC-12 cells. Food Sci. Biotechnol. 24: 2219-2227.

26. Xie C, Xie Z, Xu X, Yang D. 2015. Persimmon (Diospyros kaki L.) leaves: a review on traditional uses, phytochemistry and pharmacological properties. J. Ethnopharmacol. 163: 229-240.

27. Lee JS, Kim DH, Liu K-H, Oh TK, Lee CH. 2005. Identification of flavonoids using liquid chromatography with electrospray ionization and ion trap tandem mass spectrometry with an MS/MS library. Rapid Commun. Mass Spectrom. 19: 3539-3548.

28. Kim EO, Lee H, Cho CH, Kim YJ, Kim D-O. 2011. Antioxidant capacity and anti-inflammatory effect of the ethyl acetate fraction of dried persimmon (Diospyros kaki Thunb.) on THP-1 human acute monocytic leukemia cell line. J. Korean Soc. Appl. Biol. Chem. 54: 606-611.

29. Lee MS, Lee II, Kim Y, Kim YJ, Heo HJ, Kim D-O. 2014. Inhibitory effect of the ethyl acetate fraction from astringent persimmon on $\mathrm{H}_{2} \mathrm{O}_{2}$-induced oxidative stress in HepG2 cells. Food Sci. Biotechnol. 23: 1247-1252.

30. Turkmen N, Sari F, Velioglu YS. 2005. The effect of cooking methods on total phenolics and antioxidant activity of selected green vegetables. Food Chem. 93: 713-718.

31. Xu G, Ye X, Chen J, Liu D. 2007. Effect of heat treatment on the phenolic compounds and antioxidant capacity of citrus peel extract. J. Agric. Food Chem. 55: 330-335.

32. Lee M-R, Moon S-H, Choi A-R, Lee S-C, Ahn K-H, Park H-R. 2011. Neuroprotective effects of extracts from Diospyros kaki L. peel. Korean J. Food Cook. Sci. 27: 67-73.

33. Forouzanfar F, Torabi S, Askari VR, Asadpour E, Sadeghnia HR. 2016. Protective effect of Diospyros kaki against glucoseoxygen-serum deprivation-induced PC12 cells injury. Adv. Pharmacol. Sci. 2016: 3073078.

34. Floegel A, Kim D-O, Chung S-J, Song WO, Fernandez ML, Bruno RS, et al. 2010. Development and validation of an algorithm to establish a total antioxidant capacity database of the US diet. Int. J. Food Sci. Nutr. 61: 600-623.

35. Lee YA, Cho EJ, Yokozawa T. 2008. Protective effect of persimmon (Diospyros kaki) peel proanthocyanidin against oxidative damage under $\mathrm{H}_{2} \mathrm{O}_{2}$-induced cellular senescence. Biol. Pharm. Bull. 31: 1265-1269.

36. Greig NH, Lahiri DK, Sambamurti K. 2002. Butyrylcholinesterase: an important new target in Alzheimer's disease therapy. Int. Psychogeriatr. 14(Suppl. 1): 77-91.

37. Watkins PB, Zimmerman HJ, Knapp MJ, Gracon SI, Lewis KW. 1994. Hepatotoxic effects of tacrine administration in patients with Alzheimer's disease. JAMA 271: 992-998.

38. Kulišić-Bilušić T, Katalinić V, Dragović-Uzelac V, Ljubenkov I, Kriško A, Dejanović B, et al. 2008. Antioxidant and acetylcholinesterase inhibiting activity of several aqueous tea infusions in vitro. Food Technol. Biotechnol. 46: 368-375.

39. Bilal S, Khan AL, Waqas M, Shahzad R, Kim I-D, Lee I-J, et al. 2016. Biochemical constituents and in vitro antioxidant and anticholinesterase potential of seeds from native Korean persimmon genotypes. Molecules 21: 893.

40. Choi GN, Kim JH, Kwak JH, Jeong C-H, Jeong HR, Lee U, et al. 2012. Effect of quercetin on learning and memory performance in ICR mice under neurotoxic trimethyltin exposure. Food Chem. 132: 1019-1024.

41. Ademosun AO, Oboh G, Bello F, Ayeni PO. 2016. Antioxidative properties and effect of quercetin and its glycosylated form (rutin) on acetylcholinesterase and butyrylcholinesterase activities. J. Evid. Based Complementary Altern. Med. 21: NP11-NP17.

42. Chen XN, Fan JF, Yue X, Wu XR, Li LT. 2008. Radical scavenging activity and phenolic compounds in persimmon (Diospyros kaki L. cv. Mopan). J. Food Sci. 73: C24-C28.

43. Suzuki T, Someya S, Hu F, Tanokura M. 2005. Comparative study of catechin compositions in five Japanese persimmons (Diospyros kaki). Food Chem. 93: 149-152.

44. Fu L, Xu B-T, Xu X-R, Gan R-Y, Zhang Y, Xia E-Q, et al. 2011. Antioxidant capacities and total phenolic contents of 62 fruits. Food Chem. 129: 345-350.

45. Sharma K, Ko EY, Assefa AD, Ha S, Nile SH, Lee ET, et al. 2015. Temperature-dependent studies on the total phenolics, flavonoids, antioxidant activities, and sugar content in six onion varieties. J. Food Drug Anal. 23: 243-252. 